\title{
Ciudades de vacaciones de Educación y Descanso: cuando la clase obrera española se hizo turista.
}

\author{
Ricardo Carcelén González* \\ Universidad Politécnica de Cartagena (España)
}

\begin{abstract}
Resumen: El trabajo parte de un contexto socio-económico de lenta y progresiva adquisición de los derechos de una clase obrera española que, desligada de la naturaleza tras el episodio conocido como éxodo rural, comenzaba a demandar su cuota de descanso estival desde las ciudades industriales donde desempeñaba su actividad. El texto se propone analizar el papel del Estado ante dicha demanda presentando la labor de la Obra Sindical de Educación y Descanso, especialmente con la ejecución de sus ciudades sindicales de vacaciones en el contexto previo a la irrupción del turismo masivo en España. Para ello, se realiza un estudio que permite constatar el alcance de dicha iniciativa estatal en términos de oferta y de demanda por parte de la clase obrera, a la vez que se analizan los tres casos de estudio materializados como una de las propuestas del Estado para la re-conexión entre la naturaleza y esta incipiente clase turista.
\end{abstract}

Palabras Clave: Clase obrera; Derecho a las vacaciones; Obra sindical de educación y descanso; Ciudades de vacaciones; Turismo de masas.

Holiday cities from the Trade Union Work of Education and Rest: when the Spanish working class became tourist.

Abstract: The paper is based on a socio-economic context of slow and progressive acquisition of the rights of a Spanish working class that, detached from nature after the episode known as rural exodus, began to demand its share of summer rest from the industrial cities where it developed its activity. The text proposes to analyze the role played by the State in response to this demand by presenting the work of the Trade Union Work Education and Rest, especially with the execution of their holiday cities as a turning point prior to the arrival of mass tourism in Spain. Therefore, we conducted a study to verify the scope of this state initiative in terms of supply and demand by the working class, while analyzing the three cases of study materialized as one of the proposals of the State for the re-connection between nature and this emerging tourist class.

Keywords: Working class; Right to holidays; Trade union work of education and rest; Holiday cities; Mass tourism.

\section{Introducción}

Este trabajo se cimenta en la afirmación de Ignacio Vasallo Torné1, fundador y primer Director General de Turespaña entre los años 1982 y 1987, quien señalaba la transformación de las clases trabajadoras en turistas como el punto de partida del turismo de masas en España. Pero, ¿cuándo debemos considerar que ocurrió dicha transformación?

Habría que remontarse a finales del siglo XIX cuando los trabajadores españoles comenzarían ya a demandar, desde las ciudades industriales donde desarrollaban su labor, determinados días al año para poder regresar algunos días a sus destinos rurales de origen (Muñiz, 2001). Aunque con más retraso que en otros países europeos, la incipiente clase trabajadora comenzaba a organizarse también en España representando una fuente de serios problemas para la estabilidad política y social, lo que llevaría a sucesivos gobiernos, tanto liberales como conservadores, a proponer medidas de protección de los derechos de los trabajadores.

Universidad Politécnica de Cartagena (España); E-mail: ricardo.carcelen@upct.es 
Esta situación se acentuará en el tramo central del siglo XX en España (décadas de los años 50 y 60), que se posiciona como la etapa definitiva de expansión y consolidación de las áreas metropolitanas de las principales ciudades del país, consecuencia del intenso fenómeno de industrialización experimentado tras los duros años de posguerra (López de Lucio, 1993). Todo esto desencadenaría un éxodo de las grandes masas de trabajadores desde el anquilosado entorno rural a las grandes ciudades industriales entonces en expansión, que como señala Tezanos (2002: 224), se cifra en catorce millones de migraciones en el periodo entre 1900 y 1970. La escala alcanzada por este fenómeno, sumada a la cada vez más que consolidada adquisición de derechos laborales, entre ellos, el derecho a unas vacaciones anuales remuneradas como más adelante se señala, llevará al Estado franquista a desarrollar, a través de su Obra Sindical de Educación y Descanso (OSED) una política asistencial de turismo social, con un programa de construcción de residencias y de ciudades de vacaciones para el descanso de los trabajadores españoles como principal herramienta, que perseguirá como apunta Díaz Bello (1999: 250) un doble objetivo: por un lado, el adoctrinamiento político de las masas de manera soterrada, por medio del control y la organización del tiempo libre de los trabajadores; por otro, ofrecer a las clases obreras una oportunidad única de disfrutar durante el periodo de sus vacaciones de los placeres de la vida al aire libre, re-conectando de nuevo con el entorno rural y natural de antaño.

\section{Objetivos y metodología}

Este trabajo se marca como objetivo fundamental presentar esta herramienta de las ciudades de vacaciones de la OSED como un modelo turístico en el que, a diferencia de planteamientos turísticos más tardíos, la componente masiva en cuanto a parámetros de uso se presume no estar reñida con el respeto por la naturaleza de unos conjuntos ideados para integrarse en la casi virginal orilla marítima de nuestro país a mediados del siglo XX.

Para ello, tras escudriñar el marco teórico, se ha empleado una metodología de trabajo que deliberadamente se centra en la valoración de aquellos parámetros de índole arquitectónica y urbanística cuya incidencia sobre el consumo del paisaje y del territorio resulta determinante, y cuyo abuso podría empañar el papel del ocio como aquel "mecanismo de religación con la naturaleza" al que hiciera referencia Ortiz de Mendivil (1973: 23).

El método de trabajo aborda dos etapas:

La primera de ellas busca evidenciar el carácter de uso masivo de las ciudades de vacaciones objeto de este trabajo. En ese sentido, los repositorios digitales de los principales medios de prensa activos durante el periodo de estudio (ABC y La Vanguardia Española) han resultado una fuente de información valiosa de la que recabar datos cuantificables de usuarios que nos permitan valorar esta cuestión.

En segundo lugar, se ha llevado a cabo un análisis de ocupación y repercusión de la edificación construida sobre el entorno natural para cada uno de los tres casos de estudio que conforman el parque inmobiliario de las ciudades de vacaciones de la OSED, para lo cual se ha realizado una revisión del corpus teórico sobre los diferentes casos de estudio en el aspecto cualitativo, que se ha complementado en el cuantitativo con un trabajo ex profeso de medición de parámetros realizada sobre la documentación planimétrica original de cada uno de los conjuntos.

\section{Marco teórico: cuando la clase obrera se hizo turista.}

Aunque el derecho al descanso y, por extensión, a las vacaciones remuneradas representa hoy día un derecho inalienable de los trabajadores, nos encontramos sin embargo ante un hecho considerablemente moderno, teniendo que retroceder en el tiempo, en el caso concreto de España, menos de un siglo para encontrar su origen.

En el contexto internacional, tras la finalización de la Primera Guerra Mundial en 1918, los Estados más avanzados, no democráticos, comenzarían a regular las vacaciones remuneradas para sus respectivas clases obreras. Para tal fin, Muñiz (2001a) indica cómo es determinante la labor de la Organización Internacional del Trabajo, creada tras el gran conflicto, que en 1920 organizará un Congreso Internacional sobre el Tiempo Libre de los Trabajadores, donde se concluirá sobre la necesidad y conveniencia de reducir el tiempo de trabajo, así como de la organización del tiempo libre de los productores. 
En España, durante la segunda etapa del periodo de la dictadura de Primo de Rivera, se promulga el 23 de agosto de 1926 el Código de Trabajo, un documento que procura recoger toda la normativa laboral que hasta el momento se había redactado en el país, configurando el que sería el primer texto legal en materia de regulación de los contratos del trabajo. El texto lo componía un extenso articulado (un total de 333 artículos distribuidos en cuatro libros), que a pesar de todo no tenía cabida entre sus líneas para regular las vacaciones de los trabajadores más allá de los privilegios concedidos a los aprendices en su artículo 71 (Muñiz, 2001b), haciendo así caso omiso de las recomendaciones extraídas del Congreso de 1920 en lo referente a la organización del tiempo libre de los trabajadores.

El paso definitivo hacia el reconocimiento del derecho a las vacaciones pagadas de la clase obrera de nuestro país se dará (tras un largo recorrido de más de veinticinco años, en el que se sucedió la redacción de multitud de proyectos de ley para la regulación de los derechos de los trabajadores), durante la Segunda República, periodo que transcurre desde el 14 de abril de 1931 al 1 de abril de 1939. En los inicios de este periodo, siendo Ministro de Trabajo y Previsión D. Francisco Largo Caballero, se promulgará la Ley de Contratos de Trabajo de 21 de noviembre de 1931 que, como apunta González Gómez (1983), en su artículo 56 contempla por primera vez en la historia de la legislación social española el establecimiento del derecho de los trabajadores a disfrutar de siete días de vacaciones remuneradas al año². También la Constitución republicana de 1931 en su artículo 46 tendrá en consideración, como señalan Pié y Rosa (2013), la básica reivindicación del derecho a las vacaciones pagadas.

Atendiendo de nuevo al contexto internacional, será en el año 1936 cuando la Sociedad de las Naciones adopte una nueva convención en materia de las vacaciones remuneradas, a la que se adherirán catorce países en primera instancia, y otras tantas decenas de naciones después. Con dicho acuerdo se establecía un mínimo de seis días de vacaciones para los trabajadores del comercio y de la industria. Si bien se trataba de una medida parcial, que no abordaría por igual todos los sectores laborales, sí representó sin embargo un afianzamiento del derecho a las vacaciones remuneradas como señala Muñiz (2001a), que se sumaría a los ya adquiridos en el siglo XIX como resultado de duras luchas entre clase obrera y Estado (reducción de la jornada laboral, aumento de la edad laboral y el derecho al descanso dominical). Entre los países adheridos a la citada convención, Francia y Bélgica serán unos de los más madrugadores en cuanto al reconocimiento del derecho de los trabajadores a unas vacaciones remuneradas. Ambas naciones votarán en 1936 sendas leyes que reconocerán por fin el derecho generalizado a unas vacaciones remuneradas y, como medida más novedosa, crearán además instituciones destinadas específicamente a instrumentalizar el derecho al ocio de los trabajadores.

Mientras en el contexto internacional se afianzaba el derecho a las vacaciones pagadas de la clase obrera, se fijaba mediante leyes la duración mínima de las mismas, y se creaban instituciones y organismos destinados de forma exclusiva a organizar el ocio de los trabajadores (especial mención merecen los organismos que los regímenes totalitarios en Italia y, posteriormente, en Alemania crearían para la organización del ocio proletario), en España estallaba en julio de 1936 la Guerra Civil, dando lugar a un periodo baldío en el que no se produciría ningún avance en la materia que nos ocupa. Un año antes de la finalización del conflicto, se aprobaría el 9 de marzo de 1938 el Fuero del Trabajo, una de las ocho Leyes Fundamentales del franquismo, siguiendo los pasos de su precursora fascista Carta di Lavoro (1927). Siendo éste un documento de mucha menor extensión que el Código del Trabajo de la década anterior, sí contempla sin embargo en el texto alusiones a las vacaciones remuneradas de los trabajadores ${ }^{3}$. Como novedad en nuestro país, se contempla el compromiso para la creación de instituciones cuya principal misión sería la organización del descanso de los trabajadores, hecho que resultará determinante para la transformación definitiva de la clase obrera en turista, al tener a su disposición la posibilidad de viajar a sus destinos de descanso a precios asequibles, sin que ello supusiese un desembolso significativo para los trabajadores.

Por vez primera en la historia, la clase trabajadora española asistiría a un cambio radical de su ancestral rol en la sociedad, experimentando, aunque solamente fuese por un periodo de tiempo reducido (el de sus recién adquiridas vacaciones), un sentimiento de pertenencia a lo que el sociólogo y economista estadounidense Thorstein Veblen definiría, en 1899, como la clase ociosa ${ }^{4}$ (figura 1). Antes que Veblen, en 1880, Paul Lafargue reclamaba el derecho a la pereza ${ }^{5}$ en un pequeño ensayo publicado en el diario L'Egalité como crítica desesperada del sistema capitalista, y algunas décadas después, en la misma línea que éste, el filósofo británico Bertrand Russell (1932) publicaba un ensayo elogiando a la ociosidad, una declaración de argumentos, de nuevo, en favor de la pereza: "creo que se ha trabajado demasiado en el mundo, que la creencia de que el trabajo es una virtud ha causado enormes daños". 
Figura 1: La clase ociosa, ciudad de vacaciones de Tarragona.

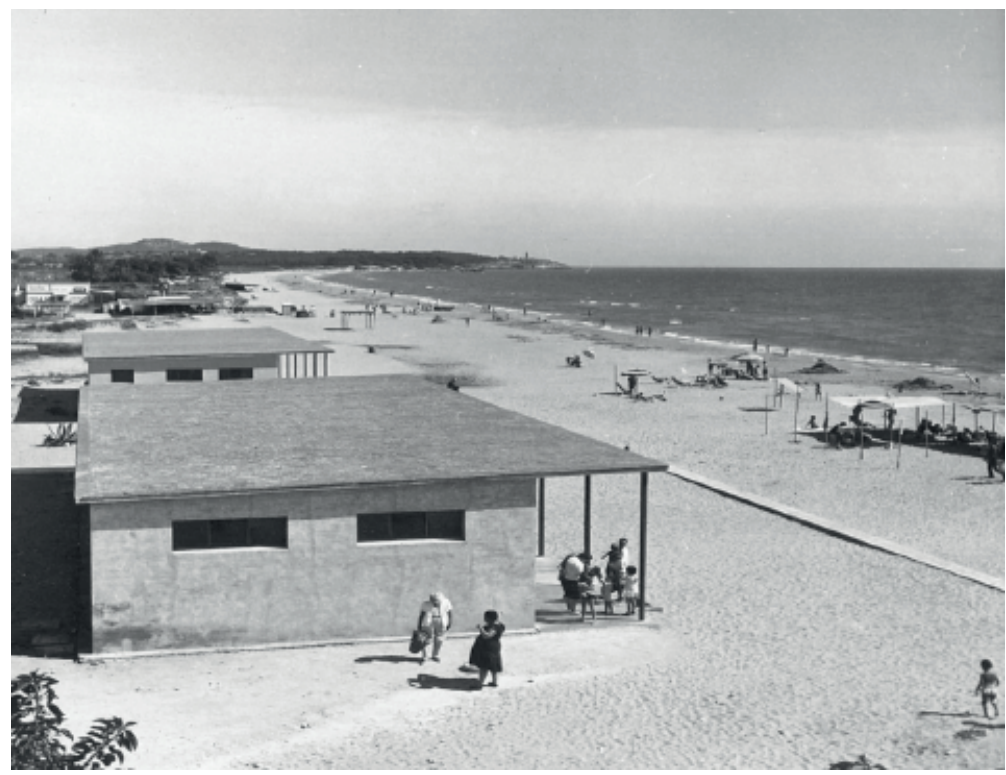

Fuente: F/33-04587-10. Archivo General de la Administración (AGA)

La Carta del Ocio, ideada en 1966 en el marco del Centro Internacional de Estudios del Ocio en la localidad de francesa de Colmar como una especie de "carta programática que definía el concepto de ocio, derechos, obligaciones, órganos, etcétera" (Ortiz de Mendivil, 1973: 23), será la que definitivamente identifique el ocio como una necesidad vital, "un elemento compensador de las condiciones del trabajo y de la vida moderna"

Será en el momento en el que los trabajadores logren su hasta entonces arrebatada ociosidad, cuando tenga lugar la transición del turismo elitista y aristocrático, asumido como un patrimonio de minorías, al conocido como turismo de masas, como señala Pié (2013: 22), en un episodio en el que inicialmente "el fenómeno turístico no es entendido como un tiempo para el ocio y el viaje a otra parte, sino como un lugar para el reposo y para recuperar fuerzas antes de regresar al trabajo". En ese mismo sentido, Loren (2008: 242) se refiere a un "entendimiento de las vacaciones como sinónimo de descanso en un entorno natural privilegiado con límites legibles", adelantando así una de las premisas que unánimemente reunirán las ciudades de vacaciones de la OSED.

Nos encontramos, pues, ante un nuevo escenario para el turismo en España ${ }^{7}$, en el que la gran masa de trabajadores aprovecharía los meses de verano para instaurar un periodo de migraciones proletarias estacionales a lo largo y ancho del país, dando lugar a lo que, con toda seguridad, sería el origen en España del "turismo popular" al que se refería Couveia (1995). Se hacía necesario entonces, tal y como establecía el Fuero del Trabajo, la creación de un organismo que procurase la organización de las vacaciones de las grandes masas de trabajadores que comenzaban a desplazarse por el país con la llegada del verano. Será el 14 de diciembre de 1939 cuando el Estado cree, para tal fin, la Obra Sindical de Educación y Descanso como uno de los primeros operadores turísticos del país que se ocuparía de la organización de las vacaciones obreras, no sólo de la gestión de plazas y de la negociación de mejoras en los precios de los transportes terrestres para sus beneficiarios, sino también de la propia ejecución ex nihilo de las instalaciones de destino, una labor que alcanzaría su punto álgido en la segunda mitad de la década de los años cincuenta con la construcción de las tres ciudades de vacaciones de Educación y Descanso en Tarragona, Marbella y Perlora, todas ellas en localizaciones costeras para satisfacer el anhelo de la orilla litoral de esta nueva clase turista (figura 2).

El historiador Alain Corbin nos recordaría, en el año 1988, cómo ese deseo de la orilla, no siempre habría existido como tal, llegando el ser humano incluso a sentir repulsión por la costa en épocas pasadas ${ }^{8}$ hasta darse un cambio de mentalidad ya llegado mediados del siglo XVIII. El autor nos acompaña a 
través de un recorrido de algo menos de una centuria en el que asistimos al despertar del interés, primero el de las clases pudientes, después el de las clases proletarias, por la costa, en un proceso tan largo y lento como el de la consecución del derecho a las vacaciones pagadas al que se ha hecho referencia.

Figura 2: El deseo de la orilla, ciudad de vacaciones de Marbella.

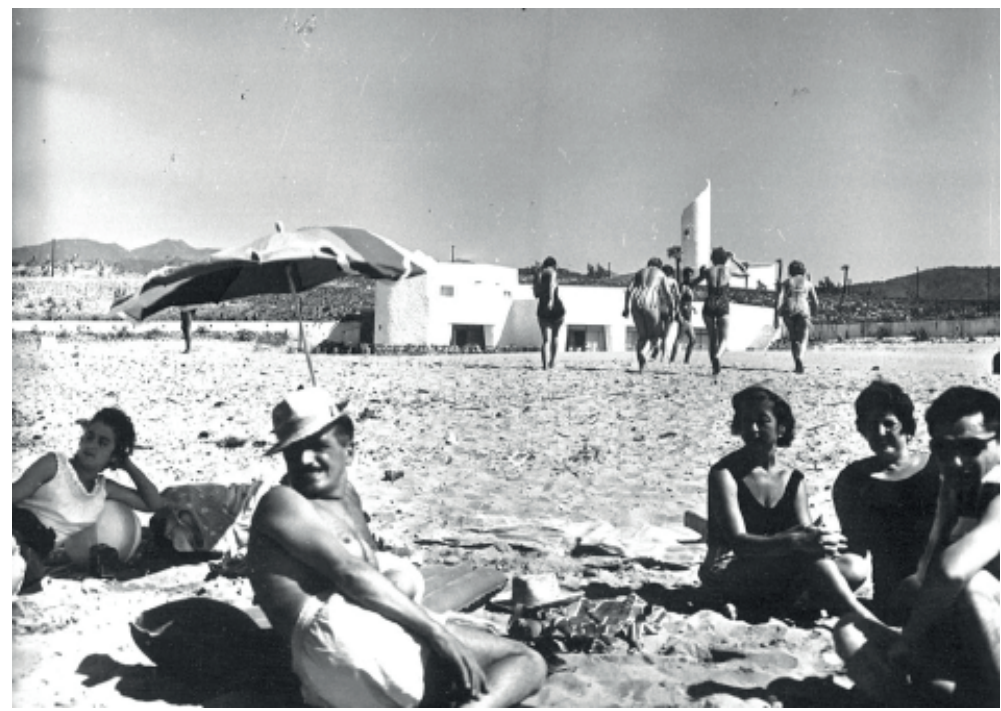

Fuente: F/33-04592-13 (AGA)

Es, sin embargo, de mayor interés para este texto el trabajo de otro historiador, Marc Boyer (2002), quién asumirá la continuación del legado de Corbin en referencia al despertar en los europeos del deseo de la orilla, atribuyendo a médicos e higienistas el mérito de promover por vez primera el interés de los bañistas hacia el mar ${ }^{9}$, escudándose en los beneficios de los baños marinos para el tratamiento, si no la cura, de las nuevas enfermedades que las insalubres condiciones de las sucias ciudades industriales habrían propiciado. Esta situación desencadenaría en el fenómeno de los balnearios termales a las orillas del mar, hecho que se consolidará durante todo el siglo XIX e incluso llegaría hasta principio del XX, dando lugar a lo que Gormsen (1981) bautizará como "la primera periferia turística litoral" en su modelo de Periferias del Placer caracterizadas por su ubicación y medio principal de transporte (Rullan, 2008). Habría que esperar a las primeras décadas del siglo pasado para presenciar lo que Boyer denominaría como "la invención del verano mediterráneo". El hecho decisivo, según el autor, para que el mar Mediterráneo comenzase a anhelarse como objeto de deseo sería el creciente interés por la práctica de la natación que, en consecuencia, favorecería a las costas de aguas templadas frente a las frías aguas que hasta ahora habrían de estar de moda en Europa ${ }^{10}$.

Finalmente, será el historiador Carlos Larrinaga (2002, 2011, 2013 y 2015) quien, siguiendo la línea de trabajo de Boyer, centre una parte de sus trabajos en conocer los detalles sobre cómo acontecería el surgimiento, y posterior crecimiento, del interés de los bañistas por las costas españolas. De igual manera que ocurriese en Europa, aunque "casi con un siglo de retraso con respecto a Inglaterra", en nuestro país comenzarían a frecuentarse las playas atendiendo a recomendaciones médicas e higienistas. Primero, serían las clases más acomodadas de la sociedad española quienes descubran los cuantiosos beneficios que para su salud guardarían las aguas marinas, si bien, en las últimas décadas del siglo XIX, ya sería una actividad totalmente extendida a las diversas clases que habrían de componer por entonces la sociedad española ${ }^{11}$, a pesar de que todavía no llegaría a alcanzar la categoría de fenómeno de masas.

El paradigma higienista se desarrollaría en lo que llegó a denominarse como playas del Norte (Guipúzcoa, Vizcaya y Cantabria), ámbito del litoral que terminaría por conformar según Larrinaga (2002: 176) el primer espacio turístico costero del país ${ }^{12}$. Esta mentalidad higienista comenzaría a ser cuestionada con el cambio de siglo, siendo entonces cuando otros factores como el ocio y la diversión 
comenzarán a entrar en la escena de las costas españolas (2002: 169), produciéndose el descenso de la asistencia a los centros balnearios tradicionales en favor de los nuevos centros lúdicos playeros en los que se ofertarían cada vez más entretenimientos como complemento de los baños de ola ${ }^{13}$.

Posteriormente, "el régimen franquista sabría ver a la perfección las potencialidades que la actividad turística tenía para una economía tan atrasada como la española y no dudaría en aprovecharlas" (Larrinaga, 2015: 82), no sin antes experimentar las posibilidades del litoral como escenario para la organización del ocio obrero objeto de este trabajo.

\section{Casos de estudio: las ciudades de vacaciones de Educación y Descanso como modelo turístico masivo y de re-conexión con la naturaleza.}

El régimen franquista emprendió una serie de etapas orientadas a la protección de las clases económicamente más débiles del país, los productores, como mecanismo a través del cual obtener la tranquilidad social, base de la prosperidad del país. Los arquitectos Monravà y Pujol describían a la perfección estas tres etapas en la memoria del proyecto de mayo de 1955 para la ejecución de una ciudad de vacaciones de Educación y Descanso en Tarragona, de la que se extrae el siguiente texto:

"Una primera etapa, pudiéramos decir, felizmente superada, es la de proporcionar seguridad y estabilidad en el trabajo; a ello ha obedecido la completísima legislación del Régimen, que ha desembocado en los beneficios de los Seguros Sociales para todos los productores, sintiéndose éstos amparados y protegidos por la acción tutelar del Estado Nacional-Sindicalista. La segunda etapa, en periodo de febril realización, es la emprendida con el objeto de dotar de viviendas sanas, modernas y acogedoras a las clases trabajadoras, a cuyo fin además de las diversas leyes dictadas al efecto de estimular y proteger la iniciativa privada, descuella por su enorme fuerza y pujanza el Plan Nacional Sindical, que a través de la Obra Sindical del Hogar e Instituto Nacional de la Vivienda, proporcionará miles de viviendas de reducidísima renta a todos los productores. No hay duda de que el complemento de estas dos etapas, y que también tiene su importancia, es el de dotar de honesto y sano esparcimiento a los obreros; en los días que celebren sus vacaciones, que la legislación les ha concedido" (Monravà y Pujol, mayo de 1955: 1).

La finalidad de la Sección de Albergues y Residencias del Departamento de Viajes, Vacaciones y Excursiones de la Obra Sindical Educación y Descanso sería precisamente esa, proporcionar alojamiento temporal a los productores españoles para que pudiesen así disfrutar de sus días de vacaciones, a un precio reducido y en lugares de gran atractivo natural y paisajístico (en zonas de playa, montaña, e incluso de interior, siempre y cuando existiese cierta riqueza cultural y artística en este último caso). Para tal fin, se crearon multitud de instalaciones de veraneo a lo largo y ancho de la geografía española, de cuya ejecución material se haría cargo generalmente la Obra Sindical del Hogar. Éstas supondrían un verdadero atractivo para los obreros, quienes durante una quincena podían disfrutar de un alojamiento particular en la playa, para él y su familia, sin que eso supusiera mella alguna en su pobre economía (Díaz Bello, 1999: 248).

Esta tercera etapa a la que se hace referencia se abordaría, a su vez, también siguiendo tres estadios diferentes ${ }^{14}$. En primer lugar, Educación y Descanso iniciaría esta actividad asistencial por medio de las residencias de verano destinadas bien a hombres, bien a mujeres, pero siempre por separado ${ }^{15}$. Estos servicios se instalarían, en origen, en inmuebles preexistentes alquilados para tal efecto, evolucionando en los años posteriores a residencias de nueva construcción ante el éxito de la iniciativa.

A esta primera fase siguió otra en la que se comenzarían a construir las residencias familiares, que permitían a los trabajadores disfrutar de sus vacaciones acompañados de su mujer e hijos, con lo que se buscaba así afianzar el vínculo español y cristiano de la familia. Monravà y Pujol escribían, en un momento ciertamente histórico para nuestro país, cuando se encontraban en pleno proceso de diseño de la que sería la primera de las ciudades de vacaciones para trabajadores en España: "Se comprende fácilmente que si estas vacaciones las disfrutase el obrero conjuntamente con sus familiares, en climas o ambientes variados, sin las preocupaciones de la vida cotidiana en el hogar habitual de residencia, se obtendría que fueran éstas más completas, tanto desde el punto de vista físico como del moral" (Monravà y Pujol, mayo de 1955: 2)

Finamente, la anterior daría lugar a una última y definitiva fase. Así, después de salpicar el territorio nacional con la construcción de multitud de residencias de veraneo para productores, la OSED decidiría dar un salto cualitativo a sus asentamientos vacacionales ${ }^{16}$, acometiendo la construcción de las ciudades de vacaciones de Educación y Descanso. La idea de poner en funcionamiento este novedoso modelo ${ }^{17}$ de asentamientos vacacionales en España debe atribuirse a quien fuese Delegado Nacional de Sindicatos 
entre los años 1951 y 1957, José Solís Ruiz, quien en un discurso transcrito en prensa con motivo de la compra de los terrenos de la entonces futura Ciudad Residencial de Tarragona, confesaba su interés desde que asumiera las riendas de la Delegación Nacional por la construcción de alguna de estas "poblaciones residenciales para el descanso del trabajador"18.

Finalmente, tres serían los asentamientos de estas características que, en la segunda mitad del siglo XX, Educación y Descanso ejecutaría ex nihilo en diferentes puntos del litoral español: la Costa Dorada de Tarragona, la Costa del Sol de Marbella y la Costa Verde Cantábrica de Perlora, Oviedo.

Ante una realidad de miles de desplazamientos nacionales anuales, la OSED llevaría a cabo acciones con el claro objetivo de favorecer la movilidad de los trabajadores, especialmente en aquellos casos de productores que en el sorteo habrían obtenido destinos lejanos respecto de sus residencias habituales. Así, a partir de 1945, la Organización Sindical habría negociado con RENFE la emisión de billetes especiales para los trabajadores afiliados a Educación y Descanso, a fin de abaratar sus desplazamientos en tren a sus destinos de vacaciones (Díaz Bello, 1999: 248) ${ }^{19}$ : "Si a un peón, familia numerosa, le corresponde una plaza en Marbella o en Tarragona, las dificultades económicas con que cuenta son imposibles de solucionar. Solamente el viaje le supone un gasto importante" (La Vanguardia Española, 15/06/65: 4).

La construcción definitiva de las tres ciudades de vacaciones de Educación y Descanso en Tarragona, Marbella y Perlora, sumado a las referidas compensaciones económicas en los desplazamientos en tren, propiciarían un panorama en el que decenas de miles de productores españoles se desplazarían cada año a lo largo y ancho de la geografía nacional para satisfacer sus demandas de ocio y descanso. En ese sentido, los datos cuantitativos extraídos de la prensa coetánea (Carcelén, 2015) evidencian una evolución creciente y exponencial del flujo de usuarios en el tiempo: en el año 1940 (año en que la OSED comenzaría su actividad) harían uso de las instalaciones de veraneo ejecutadas en ese momento un total de 3.500 productores; dieciocho años después, en 1958, con una oferta de 46 residencias y el conjunto de Tarragona, serían ya 50.000 los trabajadores que disfrutarían de sus vacaciones estivales en las instalaciones de la OSED (lo que en términos cuantitativos supone un incremento del $1.400 \%$ respecto de los valores registrados para 1940); finalmente, en 1964, con 50 residencias disponibles y las tres ciudades de vacaciones ya operando a pleno rendimiento, serían 80.000 trabajadores los beneficiarios de estas instalaciones, cifra que supone un nuevo incremento del $60 \%$ respecto de los datos obtenidos para 1958. No deben considerarse extrañas dichas cifras si se considera que, además, en el año 1950, cuando el salario medio de un obrero no cualificado en España rondaría las 603,60 pesetas al mes (20,12 pesetas al día ${ }^{20}$ ), apenas 120 pesetas ${ }^{21}$ le bastarían a un trabajador de nuestro país para costearse una estancia de hasta quince días de vacaciones en las instalaciones de veraneo de Educación y Descanso, una cifra que en el peor de los casos no superaría la quinta parte del salario que éste habría de percibir por un mes laborable, y que contrasta con los elevados costes que estos mismos obreros tendrían que asumir cuando optaban por unas vacaciones alternativas ${ }^{22}$.

Si bien este comportamiento se repetiría, originalmente, sólo durante el periodo estival, el éxito de estos conjuntos vacacionales haría que Educación y Descanso se plantease el uso en régimen permanente de los mismos. Será en 1958 cuando por primera vez la prensa nacional se refiera a este asunto ${ }^{23}$, aludiendo a una política de apertura de algunas residencias y, fundamentalmente, de las ciudades de vacaciones durante todo el año, con una estrategia evidente de romper de forma definitiva con la estacionalidad de los conjuntos. Daría así comienzo a lo que la prensa definiría como un "nuevo e interesante periodo" (La Vanguardia Española, 27/11/1958: 25) para las ciudades de vacaciones de Educación y Descanso, en el que los "fines de semana" (expresión que se emplearía en ocasiones para referirse al régimen permanente) tendrían una gran acogida entre la clase obrera del país ${ }^{24}$. El éxito de las ciudades de vacaciones de Educación y Descanso terminaría incluso por traspasar las fronteras del país, cuando la OSED comenzase a llevar a cabo acuerdos con empresas privadas, funcionariado público, sindicatos extranjeros, etcétera, a fin de establecer un programa de intercambio de productores entre países ${ }^{25}$. La primera vez que podemos documentar este programa es en una aparición en prensa tras el verano de 1957, cuando los diarios hablan del turno de cien ferroviarios alemanes, y sus respectivas familias, que con arreglo al convenio de intercambio de trabajadores cono Alemania estarían conviviendo durante sus vacaciones con 500 familias de productores españoles en la ciudad de vacaciones de Tarragona (ABC, 29/09/1957: 34). A partir de entonces, trabajadores procedentes no sólo de Alemania, sino también de Portugal, Francia, Suiza, Suecia, Austria, Inglaterra, Dinamarca y Bélgica, disfrutarían cada año de los conjuntos objeto de este trabajo ${ }^{26}$.

La optimista tendencia observada en las cifras de usuarios, sumada a la superación de límites temporales y fronterizos ponen de manifiesto, por tanto, el carácter masivo del fenómeno. Cabe ahora preguntarse qué tipo de respuesta arquitectónica y urbanística ofrecerían los conjuntos objeto de este 
trabajo que, como rasgo unívoco de identidad, compartirían la elección de emplazamientos privilegiados junto a la costa para su construcción (Sanz, 2001: 692). Esa condición especial de las localizaciones se debía fundamentalmente, como señala Gavilanes (2012: 191), al estado casi virginal que se debieron encontrar los arquitectos responsables de los diseños de las diferentes ciudades cuando iniciaron sus trabajos en la década de los cincuenta, por tanto, con anterioridad al fuerte desarrollo turístico que acontecería posteriormente. González y Santofimia (2012: 2) se referirán a las ciudades de vacaciones de Educación y Descanso como "el Caballo de Troya" de la ulterior ocupación del litoral español.

Partiendo de esta condición irrepetible de los emplazamientos, la respuesta que con estos conjuntos se trató de dar a los mismos mostraría una sensibilidad por el paisaje y el entorno (Méndez, 2012: 196), basándose en el aprovechamiento de las características naturales del terreno en lo que se refiere a sus particularidades topográficas y en el respeto máximo por la masa verde (Morales, 1982: 45), así como en el empleo de arquitecturas muy dialogantes con el paisaje en el que habrían de insertarse (Nebot, 2012: 273; Nebot, Márquez y Fernández, 2014). El concepto de las ciudades de vacaciones de Educación y Descanso se basaría en el desplazamiento del trabajador lejos de las poco salubres ciudades, a localizaciones enclavadas en un territorio natural en el que paisaje, clima, realidad litoral, etcétera, constituirán el soporte territorial cuya integridad y continuidad — cotas, geometría, vegetación, en definitiva, su lectura como elemento único, que conserva su identidad natural-se procuraría garantizar en estos conjuntos vacacionales. Loren (2008: 243) concluiría que "la arquitectura, por tanto, no procede a una delimitación material de las áreas de influencia de las construcciones, sino que se posa sobre el terreno, distinguiendo claramente el componente natural del artificio arquitectónico".

La elección de los emplazamientos no habría de ser caprichosa, sino que para la construcción de las tres ciudades de vacaciones de Educación y Descanso se optaría por tres posiciones que dividieran toda la longitud del litoral español en porciones equivalentes ${ }^{27}$ para minimizar así, en la medida de lo posible, los desplazamientos de los trabajadores a lo largo de la geografía española (figura 3).

Figura 3: Localización de las tres ciudades de vacaciones.

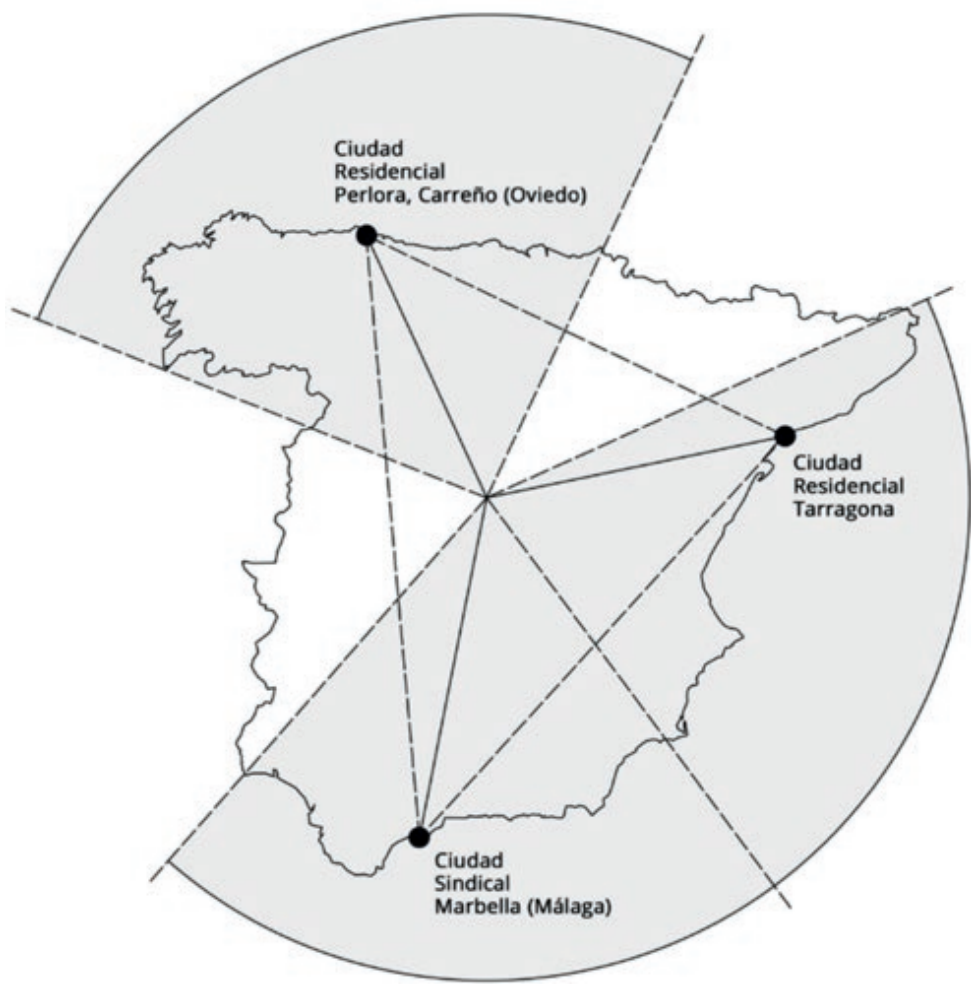

Fuente: Elaboración propia. 
Medina nos recuerda la imagen tan desgastada que el fenómeno turístico tiene entre aquellos teóricos sociales cuyos trabajos se centran en la teoría y análisis de su desarrollo. "La imagen más difundida del turismo es la de un fenómeno de masas, una horda dorada que destruye el medio ambiental [...]" (2012: 23). Durante las primeras décadas tras la explosión del fenómeno turístico masivo, algunos autores se empeñarían en denominar al mismo como la "industria sin chimeneas". Sin embargo, y desde la década de los años setenta, cada vez son más quienes cuestionan la idoneidad del término, como es el caso del experto en turismo Ernest Cañada, que no titubea a la hora de referirse a este eslogan como "un gran absurdo", alegando para ello cómo la huella ecológica que genera la industria turística tal y como hoy la conocemos, resulta plenamente insostenible ${ }^{28}$. Resulta evidente que el concepto de sostenibilidad era desconocido en la década de los años cincuenta, cuando se ejecutarían las tres ciudades de vacaciones de Educación y Descanso, si bien algunos de los aspectos que se han apuntado aquí, como el intento de preservación del paisaje natural o la reducción de los desplazamientos de los trabajadores gracias a una meditada selección de emplazamientos podrían acercar este modelo al concepto de turismo sin chimeneas referido.

Finalmente, recurriendo ahora a términos cuantitativos, se ha elaborado la siguiente tabla que recopila los principales parámetros arquitectónicos y urbanísticos ${ }^{29}$ (superficie de parcela, densidad, superficies construidas y ocupación) de cada una de las tres ciudades de vacaciones ejecutadas por la OSED en la década de los años 50 y 60: Tarragona, 1955-1957 (figura 4), Marbella, Málaga, 1956-1962 (figura 5) y Perlora, Oviedo, 1955-1967 (figura 6).

\section{Tabla 1: Parámetros arquitectónicos en las ciudades de vacaciones de Educación y Descanso.}

\begin{tabular}{|l|r|r|r|}
\hline & \multicolumn{1}{|c|}{$\begin{array}{c}\text { Ciudad } \\
\text { Residencial de } \\
\text { Tarragona }\end{array}$} & $\begin{array}{c}\text { Ciudad } \\
\text { Sindical de } \\
\text { Marbella }\end{array}$ & $\begin{array}{c}\text { Ciudad } \\
\text { Residencial de } \\
\text { Perlora }\end{array}$ \\
\hline Superficicie de parcela/actuación & $133.188 \mathrm{~m} 2$ & $228.974 \mathrm{~m} 2$ & $347.806 \mathrm{~m} 2$ \\
\hline Densidad & $13,5 \mathrm{viv} / \mathrm{ha}$ & $7,3 \mathrm{viv} / \mathrm{ha}$ & $7,88 \mathrm{viv} / \mathrm{ha}$ \\
\hline Superficie total construida & $18.074,67 \mathrm{~m} 2$ & $16.582,78 \mathrm{~m} 2$ & $31.195,33 \mathrm{~m} 2$ \\
\hline $\begin{array}{l}\text { Superficie construida de } \\
\text { equipamientos }\end{array}$ & $10.007,70 \mathrm{~m} 2$ & $6.896,98 \mathrm{~m} 2$ & $17.946,75 \mathrm{~m} 2$ \\
\hline Superficie construida de alojamientos & $8.066,97 \mathrm{~m} 2$ & $9.685,80 \mathrm{~m} 2$ & $13.248,58 \mathrm{~m} 2$ \\
\hline Ocupación total & $14.402 \mathrm{~m} 2(10.8 \%)$ & $14.914 \mathrm{~m} 2(6.5 \%)$ & $28.581 \mathrm{~m} 2(8.2 \%)$ \\
\hline Capacidad máxima por turno & 1.152 residentes & 829 residentes & $1.370 \mathrm{residentes}$ \\
\hline Número total de camas alojativas & 816 camas fijas & 682 camas fijas & $1.096 \mathrm{camas} \mathrm{fijas}$ \\
\hline Densidad bruta de camas alojativas & 61,27 camas/ha & 29,78 camas/ha & 31,51 camas/ha \\
\hline
\end{tabular}

Fuente: Elaboración propia a partir de Carcelén, 2017.

Dicha tabla resulta determinante para analizar el grado de consumo del paisaje que cada uno de los conjuntos supondría en el momento de su ejecución, y así valorar su potencial como la herramienta de religazón entre clase obrera y naturaleza a la que se hacía referencia. Para ello, basta detenerse en los bajos porcentajes de ocupación del territorio y de superficies construidas respecto de las superficies totales de las parcelas originales como característica común a los tres conjuntos, lo que resulta un claro indicador del interés de la OSED por preservar los privilegiados entornos naturales donde habrían de insertarse cada una de las tres ciudades de vacaciones objeto de este trabajo. 
Figura 4: Ciudad Residencial de Tarragona.

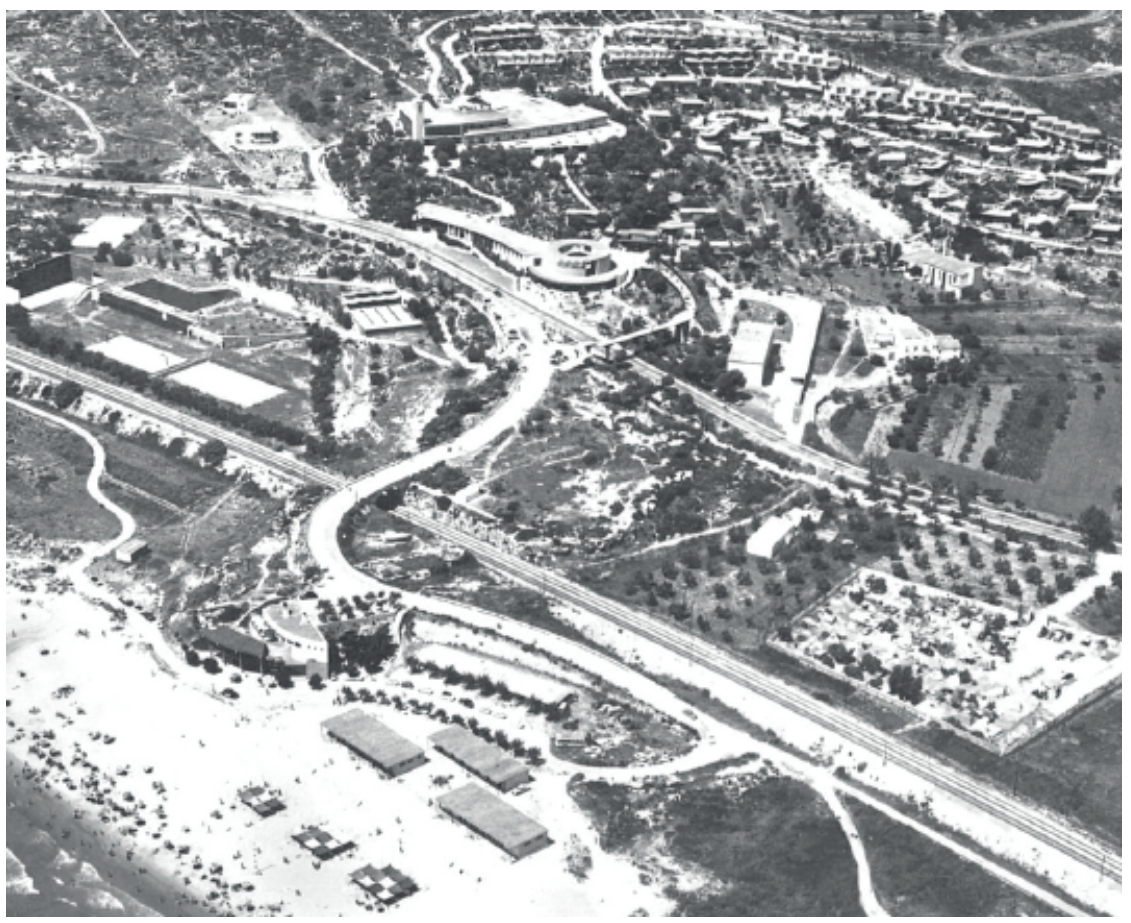

Fuente: F/33-04445-03 (AGA).

Figura 5: Ciudad Sindical de Marbella.

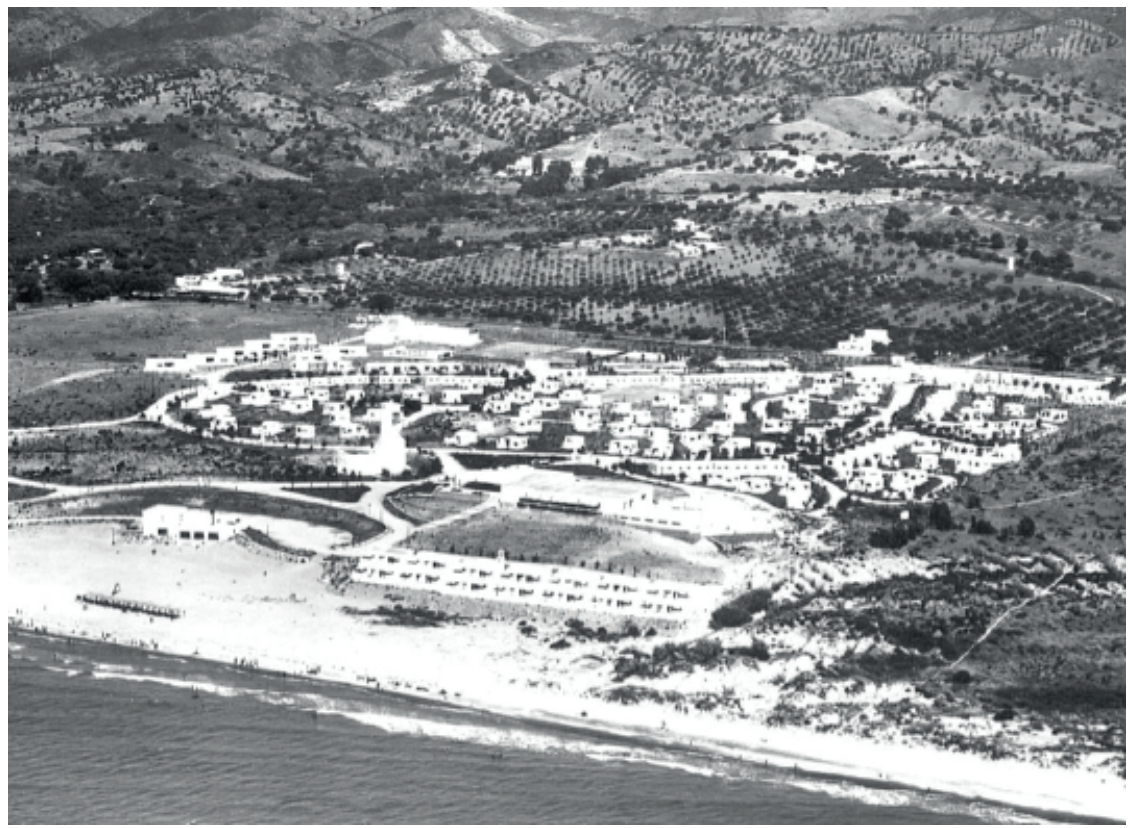

Fuente: F/33-04564-07 (AGA). 
Figura 6: Ciudad Residencial de Perlora.

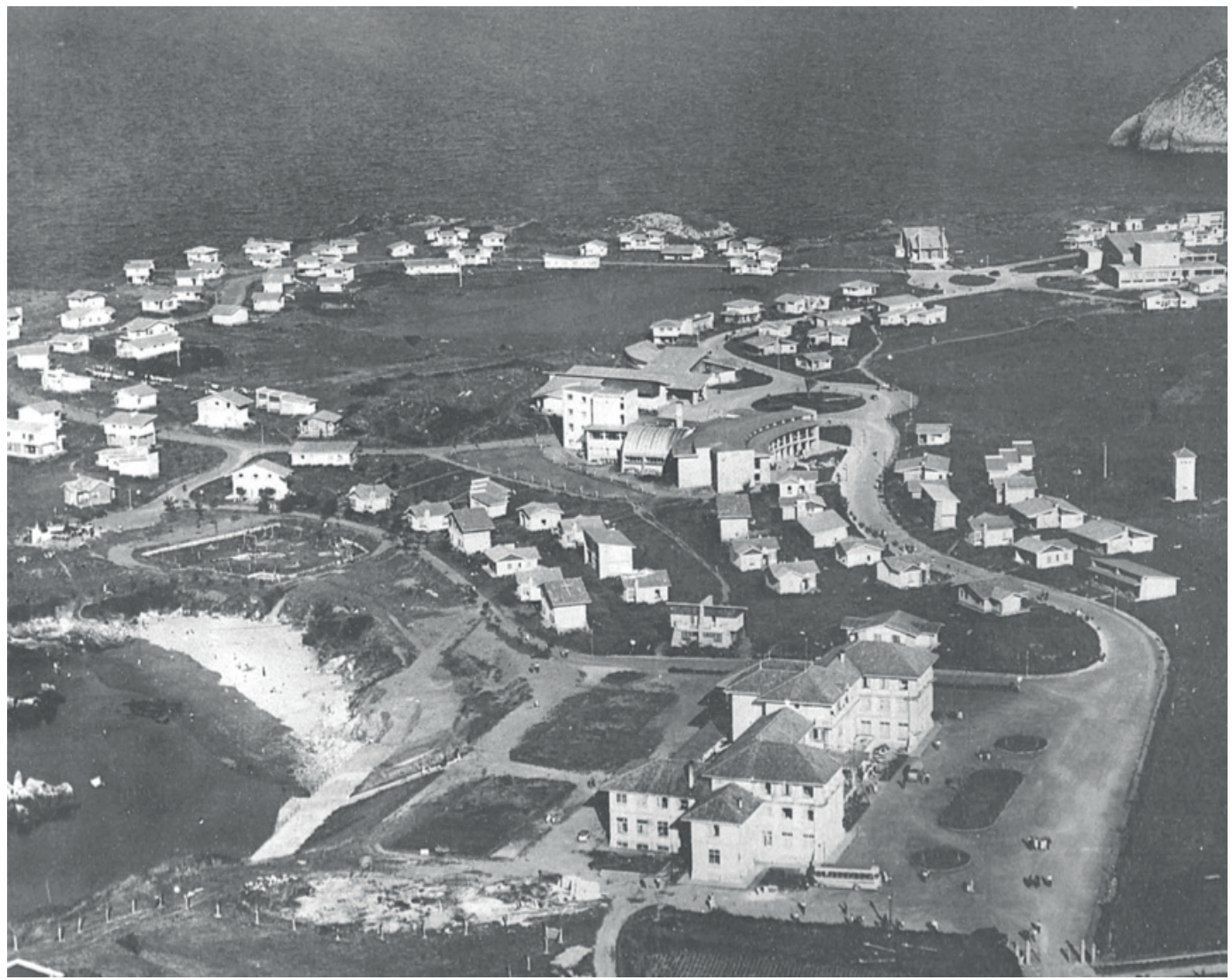

Fuente: F/33-04592-11 (AGA).

\section{Conclusiones.}

La construcción de sus propios destinos de vacaciones para satisfacer la demanda de ocio estival y el deseo de la orilla de la clase obrera del país, las negociaciones para la bonificación en el transporte para los trabajadores beneficiarios de su política asistencial, la instauración de un régimen permanente en el uso de sus instalaciones vacacionales, así como la puesta en funcionamiento en última instancia de un programa de intercambio y movilidad internacional, es lo que nos lleva en este trabajo a considerar a la Obra Sindical de Educación y Descanso como un operador turístico pionero en España, en un contexto en el que la clase obrera comenzaba a ser turista.

En este trabajo se ha tratado de evidenciar cómo, al menos durante los dos decenios que transcurrirían entre los años 1940 y 1960, Educación y Descanso se habría hecho con la hegemonía sobre el control y la planificación del descanso proletario, así como su organización en el territorio litoral español, con unas cifras de beneficiarios que se irían superando año tras año, y de manera más significativa tras la ejecución de las ciudades de vacaciones objeto de estudio en este trabajo, que muestran un crecimiento de hasta el 1.400\% cuando se han analizado los datos extraídos para los años 1940 y 1958 . A conseguir esta hegemonía ayudaría sin duda no sólo la política de precios reducidos que se ha señalado sino también lo limitado de la oferta turística durante el periodo indicado, una circunstancia que cambiaría con la llegada de la década de los años 60, cuando se asistirá al nacimiento de los llamados turoperadores o mayoristas de viajes, donde "el turismo se preparaba, se planificaba y se organizaba como en verdaderas fábricas" (Vasallo Torné, 1983: 9), con una sistematización que les permitiría ofrecer el producto turístico 
a precios altamente económicos y competitivos, diversificando por primera vez de forma significativa la oferta de veraneo para las clases medias trabajadoras en España.

Se ha presentado, por tanto, un modelo turístico masivo que sin embargo nacería con una postura sostenible frente al paisaje, a diferencia de la actitud depredadora de los modelos turísticos que surgirían en las décadas posteriores del desarrollismo español. Ese respeto por los valores naturales de nuestro litoral se percibe no sólo en las soluciones formales aportadas por los diferentes arquitectos que idearon cada uno de los conjuntos, caracterizados como se ha señalado en el texto por la adaptación topográfica, el máximo respeto por la preexistencia vegetal o el uso de arquitecturas dialogantes con su entorno, sino que también se desprende de los bajos valores de ocupación de unas actuaciones que en el peor de los casos apenas superaría el 10\% de las superficies totales de cada emplazamiento. Los porcentajes restantes, nada residuales en este caso, hablan precisamente de la voluntad por preservar el privilegiado medio natural donde llevar a cabo la re-conexión entre clase obrera y naturaleza.

Para finalizar, conviene señalar sin embargo que el verdadero interés de este episodio de las ciudades de vacaciones para el descanso de la clase obrera española no reside solamente en las soluciones formales de diseño arquitectónico aportadas, sino en haber constituido un punto de inflexión previo a la definitiva irrupción en España del turismo de masas, a partir del cual resultará difícil encontrar planteamientos similares en cuanto a integración e inserción en el territorio litoral se refiere, ante una producción turística masiva que en las décadas posteriores asumirán una actitud mucho más agresiva y depredadora del paisaje, que difícilmente se acercará a los parámetros de densidad y ocupación del territorio de las ciudades de vacaciones de Educación y Descanso que se han constatado en este trabajo, y que nos lleva a reconocer el "valor de lo irrepetible" que formulan Nanclares y Ruiz (2014: 265).

\section{Bibliografía}

Carcelén González, R. 2015. Migraciones proletarias estacionales. Un acercamiento a las ciudades sindicales de vacaciones a través de la prensa. En Ros Sempere, M. (Dir.), I Congreso Internacional Migraciones Contemporáneas, Territorio y Urbanismo. Cartagena: Universidad Politécnica de Cartagena, Servicio de Documentación. 107-122".

Carcelén González, R. 2017. Cuando la clase obrera se hizo turista. Las ciudades de vacaciones de la Obra Sindical de Educación y Descanso. Estudio de un modelo inacabado 1955-1975 (Tesis doctoral). Universidad Politécnica de Cartagena, Cartagena.

Boyer, M. 2002. El turismo en Europa, de la Edad Moderna al siglo XX. Historia Contemporánea(25), 13-31.

Carreras de Odriozola, A. y Tafunell Sambola, X. (coords.). 2005. Estadísticas históricas de España: siglos XIX-XX. Volumen III. Bilbao: Fundación BBVA: 1225.

Corbin, A. 1993. El territorio del vacío. Occidente y la invención de la playa (1750-1840). Barcelona: Editorial Mondadori.

Couveia, A.A. 1995. Identité et encadrement international du tourisme social. Seminario Internacional de Turismo Social, Calvià (Mallorca), 16-17 noviembre.

Díaz Bello, M. 1999. En busca del obrero: la organización del consentimiento en la España franquista. En M.A. Ruiz Carnicer y C. Frías Corredor (coords.), II Congreso de Historia Local de Aragón. Huesca, 7-9 julio (actas impresas), 241-253.

Gavilanes Velaz de Medrano, J. 2012. El viaje a la Costa del Sol (1959-1969). Proyecto y transformación (Tesis doctoral). Escuela Técnica Superior de Arquitectura Universidad Politécnica de Madrid.

González Gómez, S. 1983. Antecedentes históricos de la Ley de Contrato de Trabajo de la II República: presión obrera e intentos legislativos previos. Studia historica. Historia contemporánea (1), 89-103.

González Martínez, P. y Santofimia Albiñana, M. 2010. Suburbanization and modernity in Andalusia: The case of the Mediterranean Highway and the Ciudad Sindical de Vacaciones. En Living in the Urban Modernity, 11o Congreso Docomomo Internacional, México D.F.

Gormsen, E. 1981. The spatio-temporal development of international torism, attempt at a centre-periphery model. La consummation d'espace par le Tourisme et sa Preservation. Aix-en-Provence: Centre des Hautes Études Touristiques, 150-169.

Jané Sola, J. 1975. La Economía del tiempo libre. Estudios turísticos (46), 5-27.

Lafargue, P. 2004. El derecho a la pereza. Madrid: Editorial Fundamentos.

Larrinaga Rodríguez, C. 2002. El turismo en la España del siglo XIX. Historia Contemporánea (25), 157-179. 
Larrinnaga Rodríguez, C. 2011. Termalismo y turismo en la España del siglo XX. En C. Barciela López, C.P. Manera Erbina, R. Molina de Dios Y A. Di Vittorio (eds. lit.). La evolución de la industria turística en España e Italia: Encuentro de Historia Económica 6o, 2009, Palma de Mallorca, 569-608.

Larrinaga Rodríguez, C. 2015. De las playas frías a las playas templadas: la popularización del turismo de olas en España en el siglo XX. Cuadernos de Historia Contemporánea (37), 67-87.

Larrinaga Rodríguez, C. y Vallejo Pousada, R. 2013. El turismo en el desarrollo español contemporáneo. TST. Transportes, Servicios y Telecomunicaciones (24), 12-29.

López de Lucio, R. 1993. Ciudad y urbanismo a finales del siglo XX. Valencia: Servicio de Publicaciones. Universitat de Valencia.

Loren Méndez, M. 2008. La modernidad española como relato de las periferias. Laboratorio arquitectónico y visiones urbanas en alejado sur íbero. Apuntes (Volumen 21, número 2), 234-251.

Medina, J.C. 2012. Re-construcción de la cultura y del espacio turístico. Turismo, cultura e desenvolvimiento [online]. Campina Grande: EDUEB, 21-47.

Morales Folguera, J.M. 1982. La Arquitectura del Ocio en la Costa del Sol. Marbella, Málaga: Universidad de Málaga. Servicio de Publicaciones e Intercambio Científico.

Muniz Aguilar, D. 2001a. La política de Turismo Social. Málaga: Consejería de Turismo y Deporte, Junta de Andalucía.

Muniz Aguilar, D. 2001b. Evolución histórica de la política de Turismo Social española. En Estudios Turísticos (147), 141-156.

Nanclares, F. y Ruiz, N. La Ciudad Residencial de Perlora. Lo moderno de nuevo. Arquitectura en Asturias 1950-1965 (250-265). Madrid: La Micro.

Nebot Gomez de Salazar, N. 2012. El tour de las marinas. De la invención a la regeneración del paisaje (Tesis doctoral). Escuela de Arquitectura de Málaga. Universidad de Málaga.

Nebot Gomez de Salazar, N., Márquez Ballesteros, M.J. y Fernández Contreras, R. 2014. Escenografías del turismo: del Regionalismo Crítico al Folclore Banalizado. Invita la Casa. Estudios de arquitectura y urbanismo (1), 18-31.

Ortiz de Mendivil, J. 1973. Ocio y turismo. Estudios turísticos (38), 21-38.

Pie I Ninot, R. 2013. Las arquitecturas del turismo: las piezas mínimas. En R. Pié i Ninot y C.J. Rosa Jiménez (ed.). Turismo Líquido (16-39). Barcelona: Instituto Hábitat Turismo Territorio a través de Iniciativa Digital Politècnica (UPC), Universitat Politècnica de Catalunya y Universidad de Málaga.

Pie I Ninot, R. y Rosa Jiménez, C.J. (ed.). 2013. Turismo Líquido. Barcelona: Instituto Hábitat Turismo Territorio a través de Iniciativa Digital Politècnica (UPC), Universitat Politècnica de Catalunya y Universidad de Málaga.

Rullan, O. 2008. Reconversión y crecimiento de las zonas turísticas. Del fordismo al postfordismo. Destinos Turísticos: viejos problemas, ¿nuevas soluciones? Cuenca: Ediciones de la Universidad de Castilla la Mancha, 587-624.

Sanz Díaz, C. 2001. La Ciudad Residencial de Perlora: espacio de ambigüedad territorial, social, ideológica y constructiva. En J. Henares Cuéllar, G. Castillo Ruiz, M. Pérez Zalduondo e I. Cabrera Garcia (coords.), Congreso Dos Décadas de Cultura Artística en el Franquismo, (1936-1956), volumen 2. Granada (actas digitales), 689-701. [Consulta: 03/02/2016].

Tezanos Tortajada, J.F. 2002. España: estructura y dinámica social. En Actas del IV Simposio de Historia Actual, Logroño, 17-19 octubre 2002.

Tomilllo Castillo, A. y Sanz Díaz, C. 2012. Las ciudades sindicales en el periodo franquista. En International Conference Intervention Approaches for the 20th Century Architectural Heritage, Madrid, 14-16 junio 2011 (actas digitales).

Russell, B. 2000. Elogio de la ociosidad. Barcelona: Editorial Edhasa.

Vasallo Torné, I. 1983. El turismo de masas en España. Estudios turísticos (80), 3-14.

Veblen, T. 1944. Teoría de la clase ociosa (The Theory of the Leisure Class. An Economic Study of Institutions. Macmillan Company. Primera edición en inglés: 1899). México: Fondo de Cultura Económica.

\section{Notas}

1 Vasallo Torné, I. (1983). El turismo de masas en España. Estudios turísticos (80): 6. "Cuando las clases obreras se hacen turistas, aparece el turismo de masas".

2 "El trabajador tendrá derecho a un permiso ininterrumpido de siete días, al menos si su contrato de trabajo ha durado un año. El patrono, de acuerdo con el obrero, determinará la fecha en que éste haya de comenzar la vacación. El disfrute de ésta no supone descuento alguno del salario que gane el trabajador [...]" (Gaceta de Madrid 326, 1931: 1135). 
3 "Todo trabajador tendrá derecho a unas vacaciones anuales retribuidas para proporcionarle un merecido reposo, organizándose al efecto las instituciones que aseguren el mejor cumplimiento de esta disposición. Se crearán las instituciones necesarias para que en las horas libres y en los recreos de los trabajadores, tengan éstos acceso al disfrute de todos los bienes de la cultura, la milicia, la salud y el deporte" (Fuero del Trabajo, 1938: Declaración II, 5 y 6).

4 Veblen (1944: 47) aseguraba que el trabajo se habría convertido en "algo inevitablemente deshonroso".

5 Boyer (2002: 15) aclara cómo la pereza, aquí, hace referencia al "derecho de los trabajadores a parar de trabajar".

6 Algunos autores, como José Jané Solá (1975), irán más allá al afirmar que "no hay que ver el ocio solamente como un elemento compensador, sino que hay que desapuntalar el concepto de ocio de su apoyatura laboral; se ha vuelto un concepto ingrávido de esta nueva sociedad que se ha dado en denominar la sociedad opulenta".

7 "Pasma pensar la honda transformación que en la sociedad española se ha experimentado en los últimos quince años. Instituciones, facilidades y gracias que antes solo alcanzaban a determinados núcleos, son hoy el patrimonio de la amplia masa social especificada (los productores), más que por virtud del disfrute de unos medios materiales, por unos méritos o unas facultades superiores. Llévanos a esta reflexión la verificación fiel de una conquista que si al parecer intrascendente, habla por sí misma con razón aplastante de aquella honda transformación a que nos referimos. Concretamente se refiere al derecho del veraneo. El veraneo ya no es un artículo de lujo, sino un medio para mantener y elevar la sanidad espiritual y física mediante la debida y adecuada recuperación de fuerzas" (El veraneo de los productores. La Vanguardia Española, 15.06.1957: 6).

8 "La literatura antigua había presentado el mar como un lugar enigmático por excelencia y tradicionalmente se había mantenido una imagen de miedo y repulsión a lo largo de los siglos" (Larrinaga, 2002: 167).

9 "Como contrapartida, el bañista apenas dispone de libertad: el médico prescribe el balneario, la hora, la duración, el lugar de sus ejercicios; fija el número de baños de la temporada" (Corbin, 1993: 105).

10 "No se trataba todavía de un modelo alternativo al de las playas frías, sino complementario" (Larrinaga, 2015: 76).

11 "El proceso de imitación del que hablara Marc Boyer (2002: 27) había tenido resultados" (Larrinaga, 2011: 8).

12 "Aún siendo cierto que fueron las playas del Cantábrico las más visitadas y apreciadas en la segunda mitad del siglo XIX, habría que decir que no fueron las únicas frecuentadas por los españoles. En efecto, también en Andalucía se desarrollaron algunos centros turísticos" (Larrinaga, 2002: 177).

13 "Las ganas de ocio, de diversión y de separar el tiempo de trabajo del tiempo de no trabajo progresivamente iba ganando más adeptos. Capas cada vez más amplias de la sociedad optaban por reservarse unos días de vacaciones, donde lo que poco a poco empezaba a primar más era el tiempo de ocio. Por eso, para los centros balnearios la competencia que hacían las localidades con playa no era algo baladí" (Larrinaga, 2011: 33).

14 "La Delegación Nacional de Sindicatos, a través de su Obra Sindical de Educación y Descanso, ha dedicado especial atención al descanso y veraneo de los trabajadores, cubriendo etapas varias con innegable efecto", señalaba el Ministro Secretario General en un Consejo de Ministros que debatía sobre la construcción de una ciudad residencial de verano, para trabajadores, en Tarragona.

15 "Estas vacaciones, pueden disfrutarlas actualmente en forma sumamente módica, en Residencias que al efecto están distribuidas en todos los ámbitos del país, de las que cuida la Obra Sindical Educación y Descanso. Claro es que ello no constituye una meta ideal, puesto que la sólida base familiar de los españoles, hace que los días de asueto pasados entre compañeros, y en lugares distintos a los de su residencia habitual, no sean completamente felices al tener que estar separados de la esposa e hijos que quedaron en sus hogares y no compartieron las vacaciones del cabeza de familia" (Monravà y Pujol, mayo de 1955).

16 Para quien fuera Jefe Nacional de Educación y Descanso, Alberto Fernández Galar, el modelo de las ciudades de vacaciones de Educación y Descanso "supone, por decirlo así, un perfeccionamiento pleno en la vida veraniega de las familias de trabajadores. Mucha hermandad a la vez, con la vida colectiva en el restaurante, en el cine, en la playa, etcétera, para finalmente cada familia recalar en su hotelito, aislada, y como si en su propia casa se encontrara. Total, que todo esto supone al trabajador español acercarse a unos estratos en los que años atrás no podía soñar" (Diario Español en Tarragona, 31/01/1956: 12).

17 "España, dijo, es la primera en el mundo que ha acometido este ambicioso trabajo de levantar unas ciudades residenciales para descanso de sus trabajadores, y el resultado es el que vosotros bien conocéis a través de los días que en ella habéis vivido" (Más de cincuenta trabajadores alemanes pasan sus vacaciones en Tarragona. La Vanguardia Española, 18/10/1959: 7).

18 "Yo concebía una playa, una de esas risueñas playas, un pinar sano y frondoso; y dentro, una iglesia para pedir a Dios que nos siga ayudando; y un alegre restaurante donde el trabajador (aquí queda incompleta la transcripción del discurso) por una cantidad que estuviese de acuerdo con sus posibilidades; una biblioteca; un kiosco de música, unas instalaciones deportivas, un parque infantil. Y con todo eso, unos doscientos o trescientos pequeños chalets donde el trabajador, prácticamente casi por nada, pudiese pasar sus vacaciones" (Diario Español en Tarragona, 08/03/1955: 7).

19 En 1956, el abaratamiento del billete de tren para desplazarse a las ciudades de vacaciones de Educación y Descanso respecto de la tarifa habitual sería del 31\% del importe total del billete (La Vanguardia Española, 15/08/1956: 8). Casi una década después, en unas declaraciones de Gutiérrez del Castillo ante las cámaras de Televisión Española, se habla de una bonificación del 28\% sobre el precio habitual del billete ordinario (La Vanguardia Española, 15/06/1965: 4).

20 Salario medio efectivo en España. Año 1950. Carreras de Odriozola, A. y Tafunell Sambola, X. (coords.). (2005). Estadísticas históricas de España: siglos XIX-XX. Volumen III. Bilbao: Fundación BBVA: 1225.

21 Folleto Albergues y Residencias, Obra Sindical Educación y Descanso, 1950: "Con posterioridad a la publicación de este folleto y por el oficio circular no18/50 de fecha 6-3-50, ha sido modificado el importe de la plaza diaria en el sentido de aumentar ésta a 14 ptas, de las cuales corresponde abonar 8 ptas al productor y 6 ptas a la Organización Sindical”.

22 Entre los años 1955 y 1960, cuando el salario de un obrero no cualificado rondaría las 9.600 pesetas al año (aproximadamente unas 26,67 pesetas al día y 800 al mes), un fin de semana de vacaciones en un hotel del Escorial costaba 375 pesetas (según Ana Ortas y Víctor Peña, cuando el pasado diciembre de 2014 escribían sobre Ganar la lotería de Navidad en los años 50 para Radio Televisión Española), que casi suponía la mitad del sueldo percibido por un el obrero por un mes de trabajo. 
23 “PPara qué? No para estancias largas, para organización de unos turnos vacacionales extensos, sino para algo más sencillo y humano. Concretamente para que los productores puedan cada día en mayor escala acogerse a la hermosa y sana costumbre del fin de semana. Además, ahí están, a dos pasos, las festividades navideñas y, un poco más allá, las jornadas de Semana Santa" (Al margen de lo laboral. La Vanguardia Española, 27/09/1958: 3).

24 La Vanguardia Española, 12/12/1958: 19.

25 En la temporada de 1964, 14.000 productores españoles se habrían beneficiado de vacaciones en el extranjero gracias al programa de intercambio, que con respecto a los 94.000 productores que habrían hecho uso de las instalaciones de veraneo de Educación y Descanso aquella temporada, supondría aproximadamente un 15\% del total (La Vanguardia Española, 16/06/1965: 4).

26 El éxito del programa de intercambio se refleja en aquellas noticias que informarían sobre datos cuantitativos sobre algunos de estos turnos. Así, en la temporada de 1961, 1.500 alemanes, 200 suecos, 100 austriacos y un centenar de escandinavos habrían disfrutado de sus vacaciones en la ciudad de vacaciones de Educación y Descanso en Tarragona (La Vanguardia Española, 07/06/1961: 31). En la temporada de 1964, la cifra ya se habría incrementado considerablemente, con la visita al mismo conjunto de 3000 alemanes, 300 suecos, 120 portugueses, 80 franceses, 60 belgas y 40 austriacos (La Vanguardia Española, 21/06/1964: 41), lo que supondría un incremento de casi el 100\% en apenas 3 años.

27 "La iniciativa institucional para la creación de las Ciudades Sindicales respondía a [...] una estrategia de emplazamiento conforme a tres puntos equidistantes, diversos y convenientemente repartidos en otros tantos puntos de la costa española" (Tomillo y Sanz, 2012: 21-22).

28 "Es un gran absurdo decir que el turismo es la industria sin chimeneas". (www.elperiodico.com/es/noticias/mas-personas/ernest-canada-gran-absurdo-decir-que-turismo-industria- sin-chimeneas-5253416. Consulta: 24/01/2017).

29 Carcelén González, R. (2017). 